\title{
Esboço teórico sobre a leitura da imagem fotográfica
}

\author{
Rogério Luiz Silva de Oliveira* \\ Edson Silva de Farias*
}

Resumo: Este é um exercício teórico acerca da memória e do modo como o referido debate pode ser aplicado à leitura da imagem fotográfica. Leva-se em consideração o modo como o conceito de memória aparece no pensamento dos filósofos David Hume, Henri-Bergson e Gilles Deleuze, com o objetivo de estabelecer um referencial teórico que sirva de suporte para entender em que dimensão a fotografia se relaciona com essa faculdade. $O$ texto prioriza a importância das sensações presentes no processo de recriação de cenas passadas e o papel dos signos na relação entre passado, presente e futuro.

Palavras-chave: memória, fotografia, Hume, Bergson e Deleuze.

Abstract: This is a theoretical exercise about memory and how this debate can be applied to the reading of the photographic image. It takes into account how the concept of memory appears in the thinking of philosophers David Hume, Henri Bergson and Gilles Deleuze, in order to establish a theoretical framework that serves as a support to understand the dimension that relates to this capacity. The text emphasizes the importance of feeling present in the process of recreating scenes past and the role of signs in the relationship between past, present and future.

Keywords: memory, photography, Hume, Bergson, Deleuze

\footnotetext{
* Mestrando em Memória: linguagem e sociedade, pela Universidade Estadual do Sudoeste da Bahia - UESB. E-mail: rogeriolso@yahoo.com.br.

* Professor Doutor do Departamento de Sociologia da Universidade de Brasília - Unb. Email: nilosed@uol.com.br.
}

Latitude, vol. 4, no 2, pp. 127-134, 2010

DOI: https://doi.org/10.28998/2179-5428.20100208 
Esboço teórico sobre a leitura da imagem fotográfica

\section{Introdução}

O passado é uma sucessão de acontecimentos que jamais será contemplado em sua totalidade. Partimos do entendimento da memória, portanto, como a criação do passado. Diante dele, acredita-se ser a fotografia um artefato utilizado no modo como o criamos e imaginamos. Por meio dela temos um acesso limitado ao real. Ela não dá a dimensão precisa daquilo que está retratado. Ela traz ocultamente uma história, cujos mínimos detalhes são, em sua completude, desconhecidos.

Ao nos depararmos com signos, como os explicitados em imagens fotográficas de situações que nos são inéditas, nos deparamos com mundos que foram criados sem nós, que foram formados com outras pessoas, para ficar numa definição deleuziana. Nessa perspectiva, a fotografia é dotada de signos, cujo entendimento requer uma interpretação. Na concepção do referido autor, é como se uma fotografia consistisse no mesmo que países desconhecidos, inacessíveis.

Diante dessa delimitação da atuação da linguagem fotográfica, é possível submeter a fotografia à análise sob a perspectiva do debate sobre a memória. Levamos, sim, em consideração os conceitos trabalhados por Gilles Deleuze. Antes, estabelecemos uma argumentação que perpassa o pensamento de David Hume e de Henri Bergson. Neste texto, nos interessa demarcar o campo onde é possível estabelecer uma discussão de memória aplicável à observação da fotografia.

\section{A memória}

Trabalhando na perspectiva da imagem fotográfica como tendo sua função delimitada, no que diz respeito ao acesso à situação real, é possível trabalhar com o conceito de imaginação em contraposição ao de memória. Ou ao lado, como propõe o escocês David Hume.

Perseguindo uma definição da memória, David Hume estabelece uma comparação com o conceito de imaginação. Ele considera o homem como detentor do poder de dar livre curso à sua fantasia para inventar qualquer cena passada de aventuras. Leva em consideração a capacidade do homem de imaginar. Para esse pensador, essa característica humana levanta dúvidas e questões sobre as ideias da memória, principalmente à medida que elas se tornam muito fracas e sem vigor. É justamente nesse instante que surgem dificuldades em determinar se uma imagem provém da fantasia ou da memória, quando ela não se apresenta com as cores vivas que distinguem a segunda destas faculdades (Hume, 2001, p. 121).

Para Hume, a memória é definida como uma espécie de ideia que, ao reaparecer na mente, conserva um grau considerável de vivacidade primitiva, sendo algo intermediário entre impressão e ideia, duas espécies distintas às quais se reduzem todas as percepções humanas. Nesta argumentação, os conceitos de memória e imaginação se confundem e é preciso fazer a diferenciação. As ideias da memória são muito mais vivazes e mais fortes do que as da imaginação, e que a primeira destas faculdades pinta os seus objetos com cores mais nítidas do que as empregadas pela segunda (Hume, 2001, p. 37).

Adaptado ao debate em torno da fotografia, é como se a leitura da cena retratada desse margem às investidas da imaginação. A reiteração das ideias que se tem das informações da imagem pode ser posta, desse modo, no mesmo patamar 
de um exemplo apresentado no tratado humeano. Pela repetição de suas mentiras, diz ele, o mentiroso acaba por acreditar nelas como se fossem realidades, não se dando conta de que tudo aquilo pode ser fruto da imaginação. $\mathrm{O}$ mesmo acontecerá diante das realidades representadas na fotografia. Elas nunca fizeram parte do repertório do leitor e, por similaridade com alguma situação que ele conhece, há um convite à divagação.

Para que a memória possa aparecer na mente, as impressões precisam preparar-lhe o caminho. Sem elas, é natural o defeito ou imperfeição na faculdade de lembrança. Isso se deve ao fato de que a memória é entendida como responsável por reter a ordem e a posição das ideias. Entende-se ainda a memória como uma faculdade mediante a qual repetimos as nossas impressões. Sem elas, o exercício da memória é falho ou, em últimas consequências, inexistente.

Desta argumentação até aqui apresentada, entende-se que a relação com o passado deve respeitar, necessariamente, a experiência, caso se tenha a intenção de buscar as lembranças na memória. Quando isso não foi possível, o que ganha corpo é a imaginação, evidenciada a partir da inexistência de impressões.

Até aqui, uma lacuna parece ficar vazia e diz respeito ao modo como esse passado não-vivido é interpretado ou decifrado. $O$ referencial humeano não permite avançar nesse sentido, na medida em que o debate proposto pelo autor caminha para entender de que modo a noção de memória, associada ao aprendizado, contribui para um entendimento da natureza humana. Interessa a David Hume, nesse caso, estabelecer uma associação entre a memória e temas como a moralidade.

Em busca de uma discussão teórica que contemple a relação do presente com o passado, nossa abordagem deve seguir em outra direção. E, a saída talvez esteja em pensar que o modo como se imagina o passado tem base no presente, com vistas no futuro.

Considerando esse nível de discussão, a continuidade do presente debate teórico parece encontrar argumentos no pensamento de Henri-Bergson. Dando inicialmente um exemplo, é como se ao lermos uma fotografia levássemos em consideração o que nos é útil, a partir do presente e do passado que vivemos.

Para melhor entender, diremos que a fotografia na concepção bergsosiana pode ser caracterizada pelo que ele chama de matéria, sobre a qual age a memória. A matéria é entendida como "uma existência situada a meio caminho entre a 'coisa' e a 'representação'." (Bergson, 2006, p. 2) A matéria é ainda definida como um conjunto de imagens, sobre as quais prevalece uma: o corpo. Ele é parte integrante de um sistema de imagens e é soberano em relação a todas as outras. Interessa a Bergson entender como todas as outras imagens exteriores agem sobre esta imagem chamada corpo. Isso não se dá senão em conformidade com um exercício de memória. Ela é definida como a síntese do passado e do presente com vistas ao futuro e faz uso de um elemento sensório-motor.

O corpo recebe influências do mundo exterior e do mesmo modo influencia as imagens exteriores, produzindo movimento. Ele pode exercer sobre as outras imagens uma influência real, além de ser capaz de decidir em meio a procedimentos materialmente possíveis. 
Esboço teórico sobre a leitura da imagem fotográfica

$\mathrm{Na}$ relação da memória com o corpo, dir-se-ia que uma memória independente junta imagens ao longo do tempo à medida que são produzidas; $\mathrm{e}$ nosso corpo, vale ressaltar, é mais uma dessas imagens. O nosso corpo seria, deste modo, a última imagem que obtemos a todo momento praticando um corte instantâneo no devir em geral.

Isso quer dizer que os nossos estados passados estão presentes em todas as nossas decisões. Num exemplo, nosso caráter é formado a partir de nossa experiência vivida. Conta, para isso, com o trabalho da consciência atual que "a cada instante aceita o útil e rejeita momentaneamente o supérfluo." (Bergson, 2006, p. 171) Para entender o procedimento de (re)constituição de um fato passado, recorre-se a um processo sensório-motor.

O passado, então, nesse debate que leva ao encontro da memória, é um ponto de saída. O passado é o que não atua mais. A memória, assim, não consiste numa regressão do presente ao passado. Por isso ele enxerga que perceber é lembrar, já que a memória enriquece nosso presente com as experiências adquiridas.

Na conclusão de Bergson, estabelecida a função e delimitada a atuação de corpo e espírito, é oportuno concluir que o passado é desempenhado pela matéria e imaginado pelo futuro. Nas palavras de Bergson, a matéria não se lembra do passado porque, submetida à necessidade, ela desenvolve uma série de momentos em que cada um equivale ao precedente. Por isso entende-se que o passado é dado no presente. Seria em vão, buscar a leitura do passado no presente, caso este passado não se depositasse nele na condição de lembrança.

A conclusão de Bergson, em Matéria e Memória, é compartilhada por Deleuze na medida em que este último entende "que a memória intervém como um meio de busca, mas não é o meio mais profundo; e o tempo passado intervém como uma estrutura do tempo, mas não é a estrutura mais profunda." (Deleuze, 2006, p. 3)

Nesses termos, ele fala, então, de uma estrutura superficial que diz respeito ao presente, às sensações presentes. Mergulhar no passado não é possível, senão por meio de análise em que se leva em consideração o que se conhece.

A leitura feita por Deleuze diante da obra Em Busca do Tempo Perdido, de Marcel Proust, mostra que nesse livro não há uma exposição da memória involuntária, mas do relato do aprendizado de um homem de letras. Nesse caso, é possível apontar certo platonismo em Proust, para quem aprender é relembrar. Nesse processo de aprendizado, os signos são peças fundamentais, pois na definição deleuziana o que nos ensina algo emite signos, ou seja, "todo ato de aprender é uma interpretação de signos ou de hieróglifos." (Deleuze, 2006, p. 4) Tudo é aprendido por meio de decifração e interpretação.

$\mathrm{Na}$ análise proposta por Deleuze é estabelecida uma discussão sobre o significado da busca pela verdade. Se debruçando sobre a narrativa proustiana, ele entende que a verdade não é descoberta por afinidade, mas se trai por signos voluntários. É como se, para Proust, a verdade fosse o resultado de uma violência sobre o pensamento. E essa violência é exercida sobre nós a partir do signo.

Sobre isso, entende-se que certos signos nos obrigam a pensar no tempo perdido, na passagem do tempo, na anulação do que passou e na alteração dos 
seres. No que vale o exemplo de que rever pessoas que nos foram muito familiares é sinônimo de uma revelação, já que seus rostos não mais habituais para nós trazem, em estado puro, os signos e os efeitos do tempo. Os traços estão modificados.

Nesse processo, que continua sendo o de um aprendizado, há decepções. Isso se dá quando o objeto não nos revela o segredo que esperávamos. E a decepção é pluralista, variável segundo cada linha. A maioria das coisas é decepcionante à primeira vista, já que este primeiro contato é o da inexperiência, por não sabermos distinguir o signo e o objeto. E voltar às coisas uma segunda vez não é o bastante, pois a memória voluntária e esse próprio retorno apresentam inconvenientes análogos aos que nos impediam, na primeira vez, de experimentar livremente os signos.

Para Gilles Deleuze, uma questão é crucial para seguir nesse debate sobre a relação dos signos com o objeto: o que existe além do objeto e do sujeito? Segundo ele, o signo é sem dúvida mais profundo que o objeto que o emite, porém ainda se liga a esse objeto, ainda está semi-encoberto. Nessa perspectiva, o sentido do signo é mais profundo do que o sujeito que o interpreta.

No que diz respeito a essa discussão sobre os signos, uma contribuição é muito pertinente, quando se aborda a superioridade dos signos da arte. Ele entende que estes signos não são materiais como todos os outros signos. São signos que têm uma essência variada, ou seja, há uma diferença no modo de interpretar, decorrente da maneira pela qual encaramos o mundo. A arte permite, dessa forma, que em vez de contemplarmos um só mundo, ele seja multiplicado em mundos correspondentes à quantidade de artistas originais que existem. A obra de arte, então, não só nasce dos signos como os faz nascer.

Conforme essa concepção, o que a arte nos faz redescobrir é o tempo tal como se encontra enrolado na essência, tal como nasce no mundo envolvido da essência, idêntico à realidade. Ela porta signos em que está contido um tempo original absoluto.

Baseado na obra de Marcel Proust, dá-se seguimento à argumentação em torno dos signos e chega-se naquilo que é entendido por memória. $\mathrm{O}$ mais essencial nessa Recherche, de Proust, em A Busca do Tempo Perdido, não é a memória nem o tempo, mas o signo e a verdade. $\mathrm{O}$ essencial não é o lembrar-se, mas o aprender. Dessa forma, ele vê a memória como uma faculdade que só é capaz de interpretar certos signos.

A memória não nos dá nenhuma verdade profunda. Em termos deleuzianos, ela não nos força a interpretar alguma coisa ou a decifrar a natureza de um signo, não nos força a mergulhar como "um mergulhador em suas sondagens". (Deleuze, 2006, p. 92)

Antes de chegar a mais uma definição da memória, é possível destacar que os nomes, as coisas, os seres, estão todos abarrotados de um conteúdo que os faz explodir, resultando num processo heterogêneo de interpretação, a partir de elementos que lutam muito mais do que se conciliam. Tomando esse pensamento como base, transfere-se essa argumentação para o debate sobre a memória, acreditando que quando restituímos o passado em sua essência, a conjunção do presente com o passado parece mais uma luta do que um acordo. O que nos é 
Esboço teórico sobre a leitura da imagem fotográfica

dado, por fim, não é nem uma totalidade nem uma eternidade, mas um fragmento do tempo. (Deleuze, 2006, p. 114)

Falando sobre isso, em Proust e os Signos, são suscitadas questões levantadas por Henri Bergson. Este último é quem lembra que o todo não pode ser dado. $\mathrm{O}$ tempo, entendido como último intérprete ou último interpretar, tem o estranho poder de afirmar simultaneamente pedaços que não formam um todo no espaço, como também não formam uma unidade por sucessão de tempo.

Já em Imagem-Tempo, a evocação que Deleuze faz em relação a Bergson diz respeito ao que se chama de esquemas sensório-motores. É como se diante de certas situações, como numa leitura de imagens, levássemos em conta a nossa situação, nossa capacidade, nossos gostos. (Deleuze, 2005, p. 31)

Lembrando o que diz Bergson, Deleuze cita que nós não percebemos uma imagem inteira. Percebemos sempre menos, apenas o que estamos interessados em perceber, "ou melhor, o que temos interesse em perceber, devido a nossos interesses econômicos, nossas crenças ideológicas, nossas exigências psicológicas." (Deleuze, 2005, p. 31)

Ao falar sobre o cinema, Deleuze diz que ele não apresenta apenas imagens, mas as cerca com um mundo. Seguindo os passos de Bergson e revelando o pensamento deste último por meio dos comentários que constituem o trabalho Imagem-movimento, conclui-se que todas as imagens agem e reagem sobre as outras. O corpo é entendido como uma imagem, como um conjunto de ações e reações, sobre os quais as imagens externas agem.

A partir da discussão estabelecida por Gilles Deleuze, apreendemos, então, que imagens do passado são muito mais apresentação de novas coisas do que, necessariamente, um instrumento de lembrança. Os signos que compõem cada imagem precisam de uma interpretação, num ato em que se considera as vivências atuais de quem as interpreta. E, aqui, o conceito de lençóis do passado é fundamental para entender o esquema proposto pelo autor para explicar como se dá a relação de memória quando um leitor se depara com uma imagem referente ao passado. Cada um tem o seu próprio lençol de passado, onde estão impressas as marcas de lembranças. Faltando a alguém ter vivido experiências diante de uma cena retratada, os signos imagéticos ensinam, muito mais do que fazem lembrar e reconstituir.

\section{Fotografia e memória}

A discussão proposta nos permite entender que uma imagem antecipa outra imagem. Procedimento que, nessa linha de pensamento, é o que se pode definir, portanto, como memória. Ou seja, não se aborda a memória como a faculdade de lembrar, mas a recriação de um acontecimento com base no que nos é presente.

A fotografia de uma cena passada traz, sim, dificuldades interpretativas. Aquilo que apreendo de uma imagem fotográfica é muito mais relacionado ao meu repertório de conhecimento, do que à realidade fotografada. A relação que estabelecemos com ela é de cunho interpretativo. A partir de signos imagéticos entramos como que num jogo de decifração.

Num primeiro momento, a fotografia parece dar margem às investidas imaginárias. Porém, se avançamos no debate teórico apresentado, aquilo que 
poderia ser chamado de imaginação, na verdade, se trata de uma atualização. Quero dizer que, tal como propõe o debate bergsoniano, os elementos sensóriomotores são fundamentais para qualificar esse ato como ligado à memória. O presente ajuda o leitor a ter algum tipo de acesso ao passado fotografado, levando em consideração o que é vivenciado hoje ou que foi vivido no passado do próprio leitor. Interpreta-se com o auxílio do corpo, tal como argumenta Bergson. Recorrese aos lençóis do passado que cada um tem, reforça Deleuze.

Essa noção de memória é ainda complementada com as contribuições de Deleuze, principalmente no que diz respeito aos signos. Para tanto, considera-se a classificação de Charles Sanders Peirce, que entende os signos como algo que está no lugar de alguma coisa para alguém, em alguma relação ou alguma qualidade. Isso significa dizer que o aprendizado possível diante das imagens se dá justamente nesse jogo de atribuição de sentidos e de correlações com o que se conhece previamente. Em certa medida, nessa liberdade de recorrer a um baú de lembranças próprias, há, sim, espaço para as investidas da imaginação. No entanto, elas não colocam essas lembranças num grau especulativo diante da cena retratada. Elas despertam lembranças de outra natureza, tão reais quanto as que se tornaram ocultas na fotografia.

Um exemplo que parece resumir bem o que se propõe nesta breve comunicação é o filme argentino El Secreto de Sus Ojos. Nesse filme, produzido em 2009, a fotografia figura como uma chave central da trama. É a partir da leitura de imagens fotográficas que o personagem Benjamín Espósito, o primeiro Oficial de Justiça de um juizado, ajuda a desvendar um crime. A análise dessas imagens e a apreensão do sentido se dão por meio de uma atualização, de uma leitura de fotos feitas em momentos em que ele não esteve presente, porém, lida com a bagagem de sentidos trazida pelo investigador.

As fotografias encontradas nos álbuns do viúvo da jovem professora Lilliana Colotto, brutalmente assassinada em casa, evidenciavam um olhar apaixonado de Isidoro Gómez em direção à vítima quando eles eram muito jovens. Décadas depois essa mulher é assassinada e o caso fica sob a responsabilidade de um homem que um dia também foi apaixonado por uma jovem mulher e que também havia sido fotografado num momento em que olhava apaixonadamente para a mulher que desejava. Nesse momento em que o personagem Espósito Benjamín encontra essas fotografias antigas e compara com a foto em que ele olhava para Irene Menéndez Hastings - a Secretária do Juizado, por quem ele era apaixonado o oficial passa a trabalhar com a hipótese de que Gómez é o principal suspeito do crime.

Ele leva em consideração que daquele grupo que está na fotografia, Isidoro Gómez poderia ser capaz de ter matado Liliana, por amor. A partir de então, as investigações tomam um novo rumo e, de fato, prova-se que ele é o assassino. O filme, respeitando a devida dimensão fictícia, exemplifica, deste modo, o debate teórico aqui proposto, na medida em que evidencia essa capacidade móvel da fotografia. Uma recriação que está ligada ao que é essencial na fotografia presente no filme. 
Esboço teórico sobre a leitura da imagem fotográfica

\section{Bibliografia}

BERGSON, Henri. Matéria e Memória: ensaio sobre a relação do corpo com o espírito. Coleção Tópicos. Tradução Paulo Neves. São Paulo: Martins Fontes, 2006. DELEUZE, Gilles. A Imagem-movimento: cinema 1. Introdução e tradução Rafael Godinho. Lisboa: Assírio \& Alvim, 2004.

A Imagem-tempo: cinema 2. Tradução Eloísa de Araújo Ribeiro. Revisão filosófica Renato Janine Ribeiro. São Paulo: Brasiliense, 2005.

Proust e os Signos. Tradução de Antonio Piquet e Roberto Machado. 2. ed. Rio de Janeiro: Forense Universitária, 2006.

HUME, David. Tratado da Natureza Humana. Fundação Calouste Gulbenkian, Tradução Serafim da Silva Fontes. 